\title{
Characterization of CdS and ZnS Nanoparticle Semiconductors: for Optoelectronics Application
}

\author{
Suryajaya* \\ Physics Study Program, Universitas Lambung Mangkurat, Banjarbaru, Indonesia. \\ A.V. Nabok, A. K. Hassan, and A. Tsargorodskaya \\ Materials and Engineering Research Institute, Sheffield Hallam University, Sheffield, S1 1WB, UK
}

\begin{abstract}
In this work, $\mathrm{CdS}$ and $\mathrm{ZnS}$ semiconducting colloid nanoparticles coated with organic shell, containing either $\mathrm{SO}_{3}^{-}$or $\mathrm{NH}_{2}^{+}$groups, were deposited as thin films using the technique of electrostatic self-assembly. The films produced were characterized with UV-vis spectroscopy - for optical properties; mercury probe - for electrical characterisation; and photon counter - for electroluminescence study. UV-vis spectra show a substantial blue shift of the main absorption band of both CdS and ZnS, either in the form of solutions or films, with respect to the bulk materials. The calculation of nanoparticles' radii yields the value of about $1.8 \mathrm{~nm}$ for both $\mathrm{CdS}$ and $\mathrm{ZnS}$. Current-voltage (I-V) and capacitance-frequency (C-f) measurements of polyelectrolyte/nanoparticles (CdS or $\mathrm{ZnS}$ ) films suggest the tunnelling behaviour in the films while capacitance- voltage $(\mathrm{C}-\mathrm{V})$ and conductancevoltage $(\mathrm{G}-\mathrm{V})$ measurements suggest that these nanoparticles are conductive. The electroluminescence was detected in sandwich structures of $(\mathrm{PAH} / \mathrm{CdS} / \mathrm{PAH}) \mathrm{N}$ using a photon counting detector, but not in the case of ZnS films.
\end{abstract}

KEYWORDS: Nanoparticles, polyeectrolyte, CdS, ZnS, mercury probe, electroluminescence

\section{INTRODUCTION}

In the last decade, research on design and fabrication of nanostructured materials has rapidly grown and attracted much attention from many research groups [1]. Metal and semiconductor nanoparticles, particularly, have been generating continuous interest because of their unique electrical and optical properties $[2,3]$. Various techniques have been developed, in order to prepare metal and semiconductor nanoclusters as dispersions in organic or inorganic media or as aggregates [4, 5]. Werner Kern and Klaus K. Schuegraf [6] classified the deposition techniques in three main groups: pure physical, pure chemical and physical-chemical methods. Physical methods, such as Molecular Beam Epitaxy (MBE), Metal-Organic Chemical Vapour Deposition (MOCVD) or Sputtering deposition, are much more complicated and expensive as compared to chemical methods.

Because of simplicity and economical reasons, chemical methods have rapidly grown as an alternative to physical methods to synthesise and deposite semiconductor nanoparticles. Various chemical techniques have been already developed such as chemical bath deposition [7, 8], LangmuirBlodgett films [9-13], colloid synthesis [14, 15], reverse micelle [16, 17], core shell [18-20] and electrostatic selfassembly [21-65]. The latter method of electrostatic selfassembly (ESA) is particularly interesting, because it mimics the natural processes of molecular bonding, where the molecules adjust themselves to minimum thermodynamic

\footnotetext{
*E-MAIL: ?
}

(c) Jurusan Fisika FMIPA ITS conditions. The structures are stabilized by anion and cation groups as complementary units. The composition of each layer can be controlled by the incorporation of appropriately chosen molecules [25], and the structure of each layer can be manipulated by adjusting the deposition parameters [21, 29, $35,39]$. As a result, a very good nanosized structures, as precise as MBE, could be produced at a much lower cost. Therefore, electrostatic self-assembly has been used for the deposition of ultrathin films containing different type of molecules such as charged polymers (polyions) [21-39], dyes [40-42], nanoparticles (metallic, semiconducting, magnetic, insulating) and clay nanoplates [43-55], and bio-objects (proteins, DNA, virus) [56-65].

Nanostructured II-VI semiconductor materials have been and still are the subject of an intensive study because of their chemical stability at room temperature compared to unstable III-V compounds; the range of bandgap energies that encompass the entire visible spectrum, and direct bandgap. By far, nanoparticles of Cadmium Sulphide (CdS) and Zinc Sulphide $(\mathrm{ZnS})$ are the most studied systems among the semiconducting nanoparticles. The size dependent effect of these nanoparticles' optical and electronic properties have been studied experimentally and theoretically for possible application in photovoltaic and electroluminescence devices as well as other optoelectronics applications [66-72].

In this study, $\mathrm{CdS}$ and $\mathrm{ZnS}$ nanoparticles were prepared by aqueous-phase synthesis and deposited on solid substrate using the electrostatic self-assembly technique. The optical properties of these thin films were studied using UV-Vis spectroscopy along with the electrical characterisation using the mercury probe. The use of a nondestructive mercury contact (instead of traditional evaporated metal contacts) for electrical 


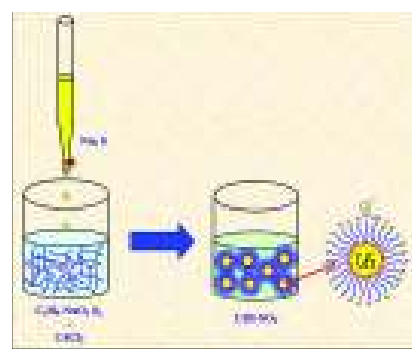

FIG. 1: The route of making colloid nanoparticles solution.

measurements in electrostatically deposited films was recently proposed by Nabok [73, 74] and established in the research group. This method allows the measurements of tunnelling current in ultrathin films containing $\mathrm{CdS}$ and $\mathrm{ZnS}$ nanoparticles which have not been attempted before. While the electroluminescence was measured by Hamamatsu H7421 Photon Counter.

\section{EXPERIMENTAL}

\section{A. Preparation of $\mathrm{CdS}$ and $\mathrm{ZnS}$ colloid nanoparticles}

In this work, the aqueous synthesis method was used to prepare electrically charged $\mathrm{CdS}$ and $\mathrm{ZnS}$ colloid nanoparticles, coated with organic shell containing either $\mathrm{SO}_{3}^{-}$or $\mathrm{NH}_{2}^{+}$groups using thiolate ligand as a capping agent. All chemicals used are Cadmium chloride, Zinc Chloride, Sodium 2-Mercaptoethane Sulphonate, Cysteamine Hydrochloride, Sodium sulphate. All chemicals used were of high purity purchased from Sigma-Aldrich.

In order to make $\mathrm{CdS}-\mathrm{SO}_{3}^{-}$colloid nanoparticles, firstly, the solution of Sodium 2-Mercaptoethane Sulphonate was mixed with Cadmium Chloride solution. The $\mathrm{Cd}^{2+}$ and $\mathrm{Cl}^{-}$ ions would form complex bonding with sulphonated species. And then when a sodium sulphide solution is added dropwise to the mixture while it is stirred (as shown in Figure 1).

Colloid nanoparticles of $\mathrm{CdS}-\mathrm{NH}_{2}^{+}$were made following the same routine but using Cysteamine Hydrochloride as a capping agent. The result is a cloudy yellow colloid solution of $\mathrm{CdS}-\mathrm{NH}_{2}^{+}$. Applying the similar routine, for $\mathrm{ZnCl}_{2}$, colloid solutions of $\mathrm{ZnS}-\mathrm{SO}^{3}$ and $\mathrm{ZnS}-\mathrm{NH}_{2}^{+}$ nanoparticles were made. All processes were performed at room temperature.

\section{B. Multilayer deposition procedures}

The electrostatic self-assembly (ESA) is used as a deposition technique. Two types of polyelectrolytes were used as binding layers for electrostatic layer-by-layer deposition of $\mathrm{CdS}$ and $\mathrm{ZnS}$ nanoparticles: polycation poly-allylamine hydrochloride $(\mathrm{PAH})$ and polyanions poly-styrene-sulfonate sodium salt (PSS), both purchased from Sigma-Aldrich. First,



FIG. 2: Electrostatic self-assembly deposition cycle.

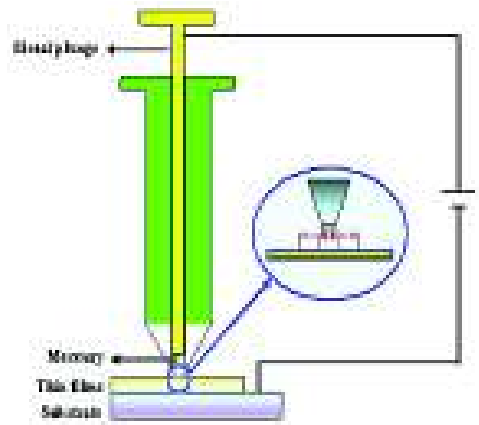

FIG. 3: Mercury probe experimental set-up.

a layer of PAH was deposited on the negatively charged substrate by dipping the sample for $20 \mathrm{~min}$. into $1 \mathrm{M}$ aqueous solution of PAH, which makes the surface positively charged. Then negatively charged $\mathrm{CdS}-\mathrm{SO}_{3}^{-}$(or $\mathrm{ZnS}-\mathrm{SO}_{3}^{-}$) nanoparticles can be deposited straight onto the PAH layer by dipping the substrate into respective colloid solution for $10 \mathrm{~min}$ (see Figure 2.). Multilayered films of $\mathrm{CdS}-\mathrm{SO}_{3}^{-} /$ PAH or $Z n S-S O_{3}^{-} /$PAH CdS can be produced by repeating these two deposition steps with intermediate rinsing the sample in Millipore deionised water. The exposure time in all consecutive dipping was $10 \mathrm{~min}$.

\section{Measurement Techniques}

1. Procedure of UV-Vis Spectrophotometry Measurements

A Varian CARY 50, UV-vis spectrophotometer was used to determine the absorption spectra of $\mathrm{CdS}$ (or $\mathrm{ZnS}$ ) colloid solutions and multilayer films deposited onto glass and quartz substrates.

2. Electrical Properties Study using Mercury Probe The schematic diagram of a mercury probe technique, similar to that used in [73], is shown in Figure 3.

3. I-V characterisation DC current-voltage (I-V) characteristics were measured 


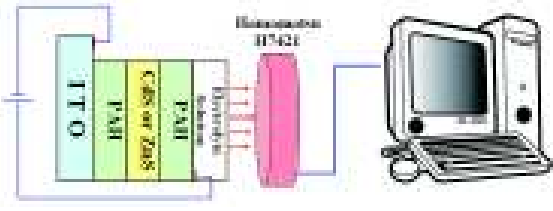

FIG. 4: Electroluminescence experimental set-up.

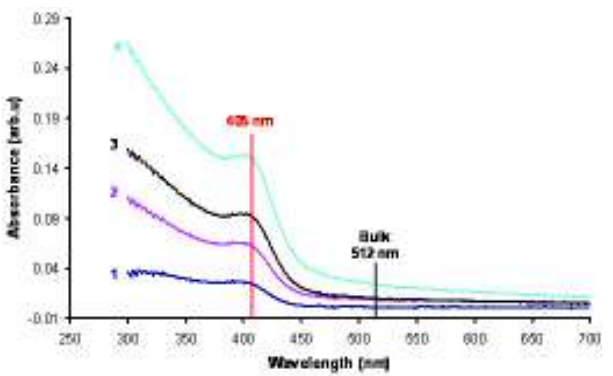

(a)

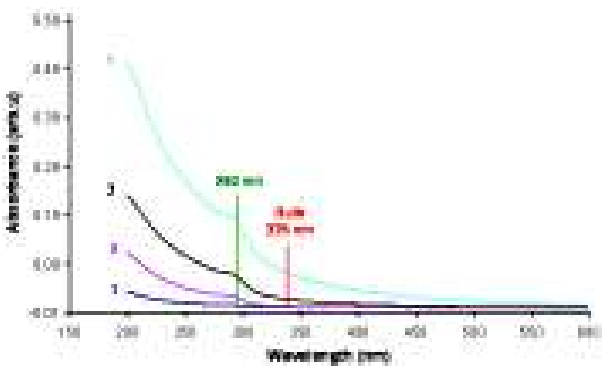

(b)

FIG. 5: UV-vis absorption spectra of PAH/ $C d S-S_{3}^{-}$(a) and $\mathrm{PAH} / \mathrm{ZnS}-\mathrm{SO}_{3}^{-}$(b) film. The numbers near respective spectra correspond to the number of polyelectrolyte/nanoparticle bilayers.

using Keithley 4200 Semiconductor Characterization System instrument. Parameters of the DC bias sweep were: the sweep range from -0.5 to $0.5 \mathrm{~V}$, and the step size of $5 \mathrm{mV}$.

\section{4. $\mathrm{C}-\mathrm{V}$ characterisation}

$\mathrm{C}-\mathrm{V}$ characteristic measurements were carried out by using Hewlett Packard 4284 A Precision LCR meter in a frequency range of $20 \mathrm{~Hz}-1 \mathrm{MHz}$. The instrument was interfaced to computer via IEEE GPIB card and controlled by dedicated software. Parameters of bias sweep were: the bias range from -0.5 to $0.5 \mathrm{~V}$, and the step size of $10 \mathrm{mV}$.

5. Electroluminescence Experiment Procedure

Electroluminescence measurements were carried out by using Hamamatsu H7421 photon counter as shown in Figure 4. The instrument was interfaced to computer using a Hamamatsu M8784 Counting Board PCI card and controlled by Hamamatsu software.

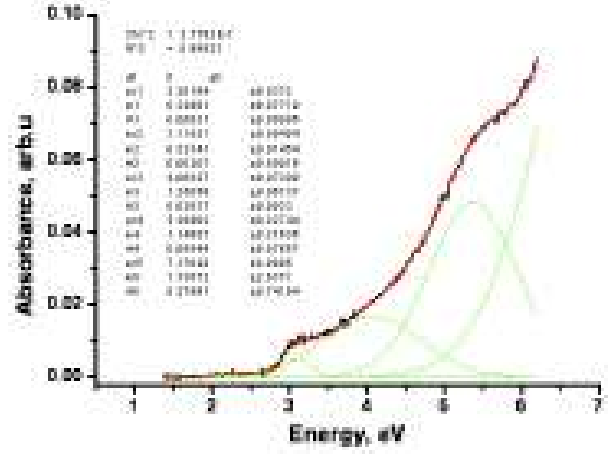

(a)

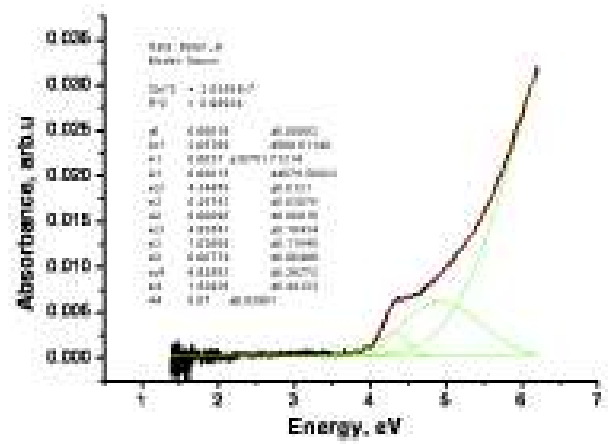

(b)

FIG. 6: Gaussian fitting of the spectra of the first layer of $C d S-$ $\mathrm{SO}_{3}^{-}$(a) and the first layer of $\mathrm{ZnS}_{-} \mathrm{SO}_{3}^{-}$(b). The experimental data (black line) was fitted using several Gaussian peaks (green line) and the result was shows by the red line.

\section{RESULTS AND DISCUSSION}

\section{A. OPTICAL PROPERTIES OF CdS AND ZnS NANOPARTICLES}

Typical absorption spectra of CdS nanoparticles embedded in organic films of PAH (for $\mathrm{CdS}-\mathrm{SO}_{3}^{-}$) and PSS (for $\mathrm{CdS}-\mathrm{NH}_{2}^{+}$) are shown in Figures 5. (a) and (b). All of them show monotonous increase in the absorption intensity, with the increase in the number of layers, which reflects the consistency of electrostatic deposition. The main absorption band at about $405 \mathrm{~nm}$ and $290 \mathrm{~nm}$ appear for CdS and $\mathrm{ZnS}$ nanoparticles, respectively. Both absorption bands are blue shifted as compared to the absorption band of bulk CdS at $512 \mathrm{~nm}$ and $\mathrm{ZnS}$ at $335 \mathrm{~nm}$.

The size of $\mathrm{CdS}$ and $\mathrm{ZnS}$ nanoparticles can be evaluated from the blue shift of the absorption bands with respect to the band gap value of bulk $\mathrm{CdS}$ as a consequence of quantum confinement effect. In this work, the radius of semiconductor clusters is calculated using Efros equation for the energy spectrum in nanoparticles of direct band gap semiconductors, having parabolic $\mathrm{E}(\mathrm{k})$ dispersion. It is assumed that the particles' radius is smaller than Bohr exciton radius. Hence, in the 
TABLE I: Energy gap and the particles' size obtained by Gaussian fitting of the absorption spectra of CdS and ZnS films.

\begin{tabular}{ccccccc}
\hline \hline & $\mathrm{E}_{1}(\mathrm{eV})$ & $\Delta E_{1}(\mathrm{eV})$ & $\mathrm{R}_{1}(\mathrm{~nm})$ & $\mathrm{E}_{2}(\mathrm{eV})$ & $\Delta E_{2}(\mathrm{eV})$ & $\mathrm{R}_{2}(\mathrm{~nm})$ \\
\hline$C d S-S O_{3}^{-}$ & $3.12 \pm 0.0048$ & 0.7 & $1.79 \pm 0.01$ & $5.37 \pm 0.2274$ & 2.95 & $1.61 \pm 0.12$ \\
$C d S-N H_{2}^{+}$ & $3.08 \pm 0.0020$ & 0.66 & $1.85 \pm 0.01$ & $5.15 \pm 0.3932$ & 2.73 & $1.67 \pm 0.24$ \\
$Z n S-S O_{3}^{-}$ & $4.34 \pm 0.0121$ & 0.66 & $1.80 \pm 0.03$ & - & - & - \\
$Z n S-N H_{2}^{+}$ & $4.38 \pm 0.0074$ & 0.7 & $1.74 \pm 0.02$ & - & - & - \\
\hline \hline
\end{tabular}

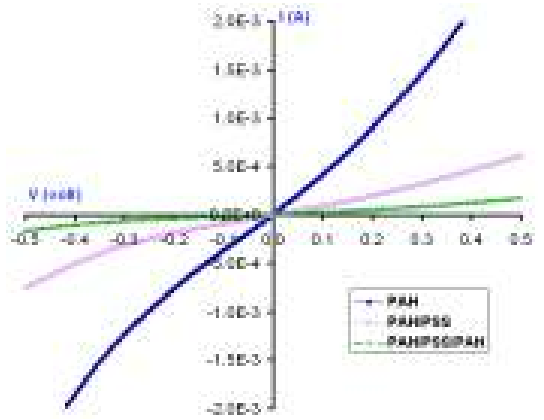

(a)

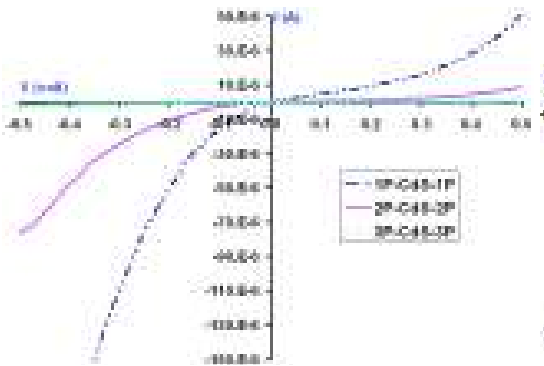

(b)

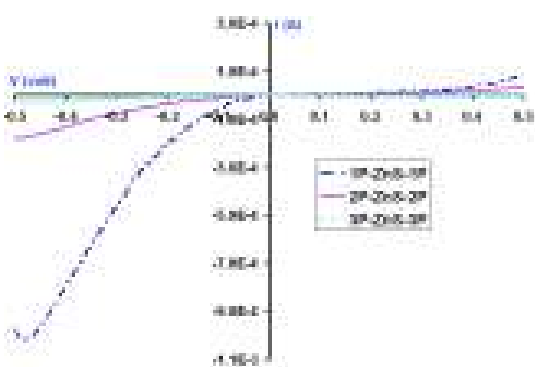

(c)

FIG. 7: Typical of DC I-V characteristics (the voltage sweep range: - 0.5 to $0.5 \mathrm{~V}$, step size: $5 \mathrm{mV}$ ) of the films: Polyelectrolyte (a), polyelectrolyte/CdS/polyelectrolyte (b), and polyelectrolyte/ZnS/polyelectrolyte (c).

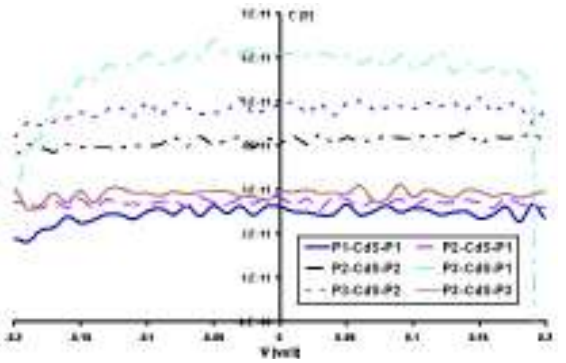

(a)

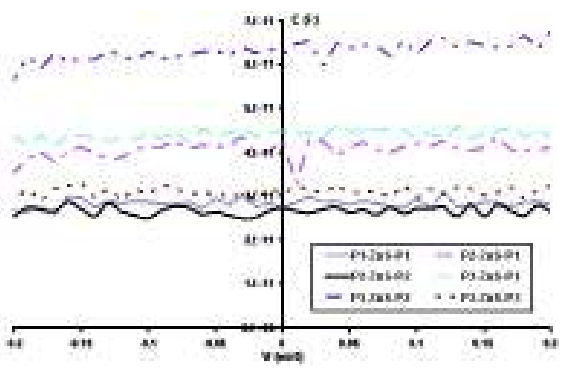

(b)

FIG. 8: C-V characteristic of sandwich structures. (ITO/insulator $/ \mathrm{CdS} /$ insulator/Hg) (a) and (ITO/insulator/ZnS /insulator/Hg) (b).

case of strong confinement, [3].

$$
E_{(n, \ell)}=E_{g}+\frac{\hbar^{2}}{2 \mu R^{2}} \phi_{(n, \ell)}^{2}
$$

where $\mathrm{E}_{g}$ is the band gap for bulk semiconductors, $\mu$ is the reduced effective mass of exciton, $\frac{1}{\mu}=\frac{1}{m_{e}^{*}}+\frac{1}{m_{k}^{*}}$, and $\phi_{(n, \ell)}$ are the roots of Bessel functions (for the ground state ).

The values of $E_{(n, \ell)}$ can be found from the exact positions of the absorption peaks. To do that, the Gaussian fitting of absorption spectra re-plotted in energy coordinates was performed similary to ref. $[11,12]$. The results are shown in Figure 6. (a) and (b). The observed energy dispersion may reflect the combination of the size distribution of nanoparticles and the presence of higher index energy levels of size quantization, that is why only the first maximum (in each spectrum) corresponding to the ground state level was chosen for further analysis. The values of $E_{(n, \ell)}=3.04 \mathrm{eV}$ (for CdS) and 4.19 $\mathrm{eV}$ (for $\mathrm{ZnS}$ ) were found for the respective positions of the first absorption bands in Figure 6 .

Using the data of energy gap obtained from the Gaussian fitting, the calculated values of $\mathrm{CdS}$ and $\mathrm{ZnS}$ particle size are summarized in Table 1. The radius of nanoparticles yield for both $\mathrm{CdS}$ and $\mathrm{ZnS}$ films were relatively the same, about 1.8 nm.

\section{B. ELECTRICAL STUDY OF CDS AND ZNS NANOPARTICLES}

\section{I-V Characteristic of Nanoparticle Films}

Typical results of DC I-V characteristics of (PAH/PSS)N films, deposited onto ITO glass, are shown in Fig. 7 (a). Voltage sweep in the range of -0.5 to 0.5 volt gave symmetrical $\mathrm{I}-\mathrm{V}$ curves. The other type of measurements with bias ranging from 0 to -0.5 , at the same spot, gave more or less the same I$\mathrm{V}$ curves. The measurements at different spots on the sample gave a slightly different value, which is believed to be caused 


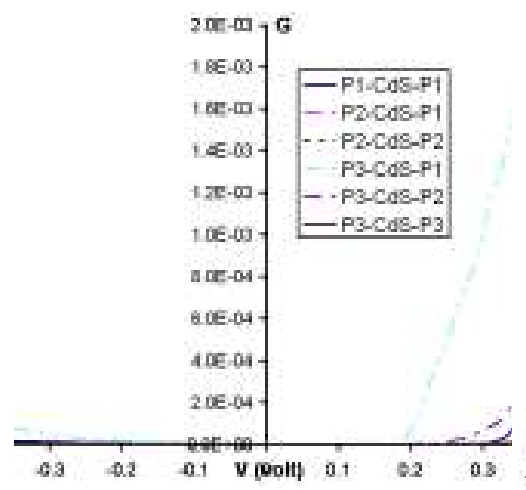

(a)

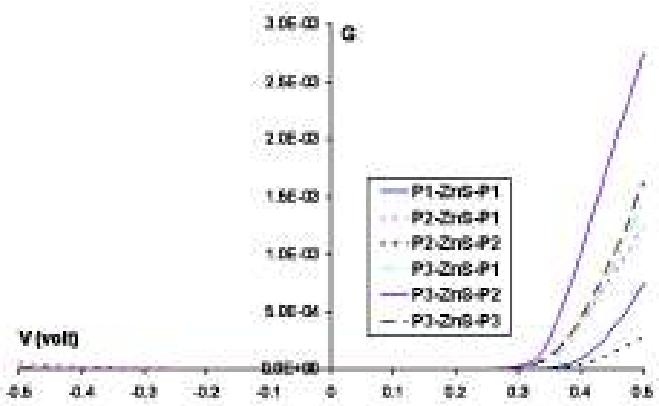

(b)

FIG. 9: G-V characteristic of sandwich structures (ITO/insulator/ dS/insulator/Hg) (a) and (ITO/insulator/ZnS /insulator/Hg) (b).

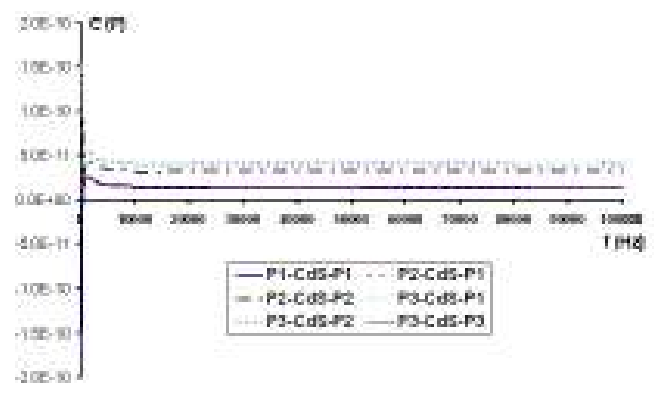

(a)

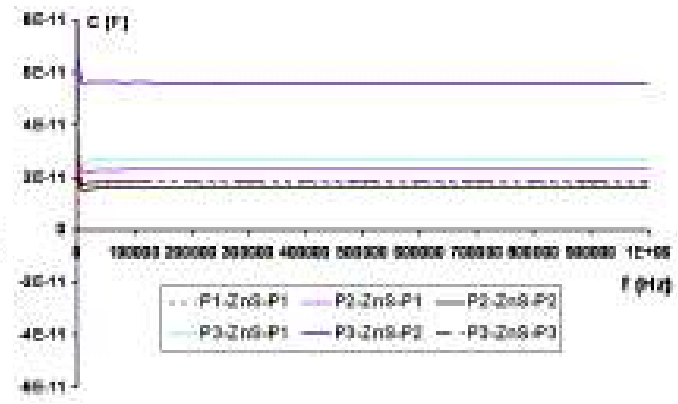

(b)

FIG. 10: C-f characteristic of sandwich structures (ITO/insulator/CdS /insulator/Hg) (a) and (ITO/insulator/ZnS /insulator/Hg) (b).

by inhomogeneous coating also reported in our previous work $[75,76]$.

The presence of $\mathrm{CdS}$ or $\mathrm{ZnS}$ nanoparticles in the films causes the decrease in film conductivity as shown in Fig. 7 (b) and (c) which is believed to be caused by the increase in the film thickness due to aggregation and intercalation of nanoparticles. It is also clearly seen that the I-V curves for both $\mathrm{CdS}$ and $\mathrm{ZnS}$ are not symmetric; the current at the positive voltage is much smaller than that at the negative one, which is maybe due to the work function difference between ITO and $\mathrm{Hg}$ electrodes. The I-V characteristics follow the $\mathrm{I} \approx$ $\mathrm{V}^{2}$ dependence.

\section{C-V characteristic of films containing $\mathrm{CdS}$ (or $\mathrm{ZnS}$ ) nanoparticles}

The AC measurements in sandwich structures as frequency dependencies of the capacitance and their AC conductance as a function of frequency represent a traditional insulating behaviour for all films studied. Figure 8 shows typical results of the $\mathrm{C}-\mathrm{V}$ measurements of sandwich structures (ITO/insulator/CdS /insulator/Hg) as frequency dependencies of the capacitance. As can be seen, the capacitances of the films were not really correlated to films thicknesses. It might be caused by the random distribution of $\mathrm{CdS}$ nanoparticles in the films.
If the system is considered as a plane capacitor, then the capacitance is defined as:

$$
C=\frac{\epsilon \epsilon_{\circ} A}{d}
$$

where A is the cross section area of the capacitor, $d$ is the separate distance, $\epsilon$ is the dielectric constant, and $\epsilon_{\circ}$ is the electric permittivity in vacuum. Typical diameter of mercury contact was $0.220 .03 \mathrm{~mm}$ giving an active device area of $0.038 \pm$ $0.001 \mathrm{~mm}^{2}$. Therefore the calculations of the dielectric constant for the highest capacitance of $0.61 \mathrm{pF}$ from Figure 8, with the film thickness of about $5 \mathrm{~nm}$ obtained from spectroscopy measurements yield the values of about 0.9 for the films containing $\mathrm{CdS}$ nanoparticles and 0.92 for $\mathrm{ZnS}$ films. The obtained values of $\epsilon$ are less than one, which means that the nanoparticles are conductive so that $\mathrm{C}-\mathrm{V}$ measurements were affected by the films conductivity only.

This result is supported by the measurements of G-V characteristic, as shown in Figure 9. It shows that the conductance was increased at the voltage of 0.2 volt for $\mathrm{CdS}$ and at 0.3 volt for $\mathrm{ZnS}$.

Figure 10 demonstrates the $\mathrm{AC}$ conductance as a function of frequency. As can be seen, the capacitance of both $\mathrm{CdS}$ and $\mathrm{ZnS}$ films is practically independent of frequency over the range of $10^{2}-10^{6} \mathrm{~Hz}$, which could be another proof of the tunnelling behaviour. 


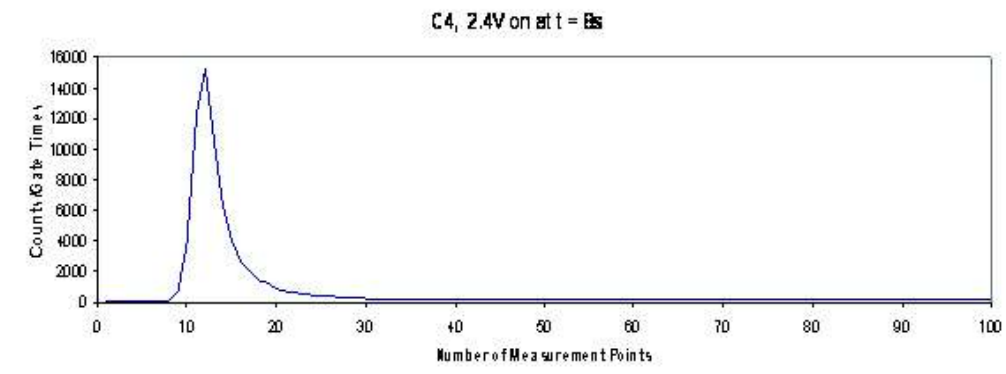

FIG. 11: The electroluminescence for a sandwich structure of $\left[\mathrm{PAH}-(\mathrm{CdS}-\mathrm{PAH})_{3}\right]$ on $\mathrm{TiO}_{2}$.

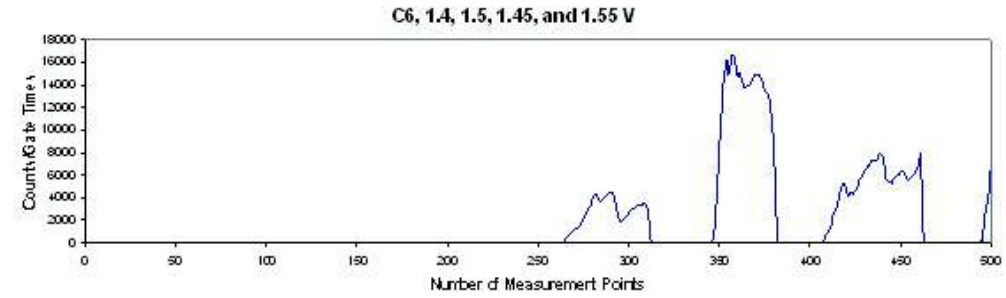

(a)

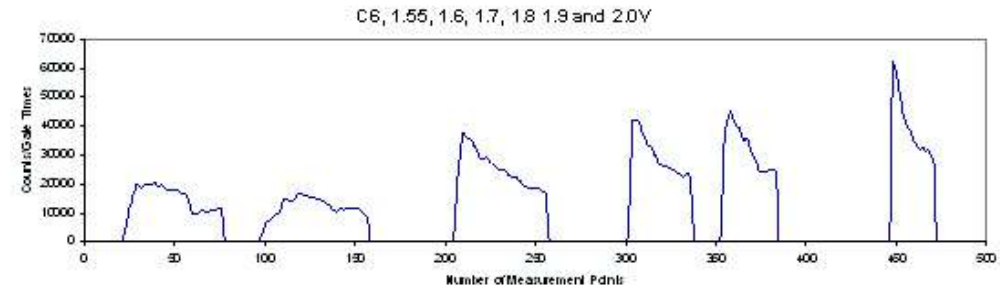

(b)

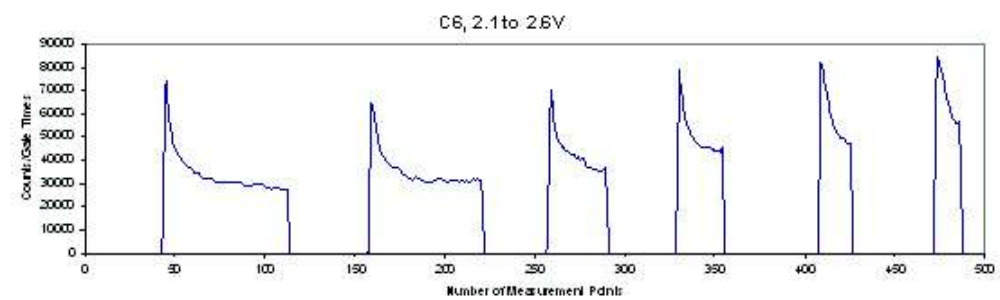

(c)

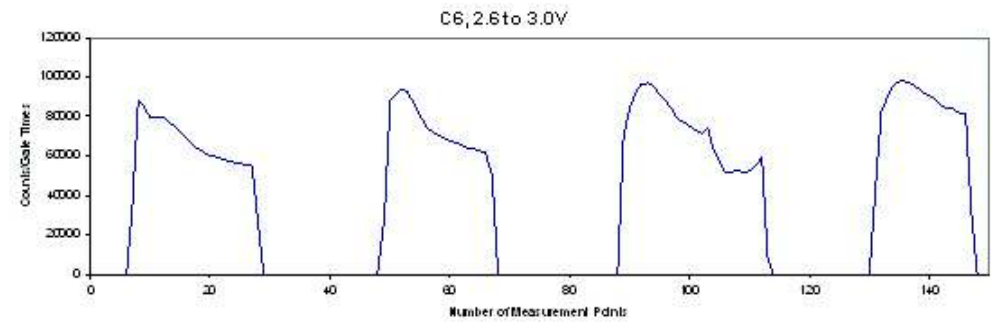

(d)

FIG. 12: The effect of step input voltage to EL intensity. 


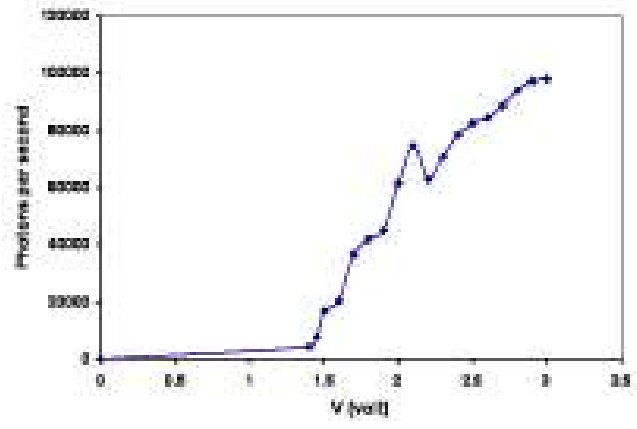

FIG. 13: The electroluminescence intensity as function of the input voltage.

\section{ELECTROLUMINESCENCE STUDY}

The electroluminescence phenomenon have been detected on samples of $\left[P A H-(C d S-P A H)_{3}\right]$ structure, deposited on $\mathrm{TiO}_{2}$ coated ITO, with 2.4 volt as the input voltage. When the voltage was switched on at $t=8 \mathrm{~s}$, the number of photon per second increases from the ambient noise to a peak of 15200 photons per second (p/s) in 4 seconds (see Figure 11.) and then decays exponentially to the value of around $150 \mathrm{p} / \mathrm{s}$, which is higher than the original noise level but small enough to be negligible.

The effect of step input voltages from 0 to 3 volts by an increasing step of 0.1 volt to the electroluminescence intensity was investigated and the results are presented in Figure 12. The luminescence was started at $\mathrm{V}=1.4$ volt, as predicted from $\mathrm{I}-\mathrm{V}$ characteristics $(1.5 \mathrm{~V}$ for $\mathrm{CdS})$. The results mostly show an irregular increase in peak count as the voltage increases.

If the highest point of each peak were taken and plotted as function of voltage, the results were illustrated in Figure 13. The curve suggests the behaviour of LED or laser with the voltage threshold at about 1.4 volt.

\section{CONCLUSION}

This work demonstrated the feasibility of the electrostatic self-assembly method to fabricate multilayered CdS (or ZnS) nanostructures onto different solid substrates such as silicon, glass, quartz, chromium/gold coated glass, and ITO. From UV-Vis spectroscopy measurements, the position of the main absorption band obtained for the films containing CdS and $\mathrm{ZnS}$ have the values of $405 \mathrm{~nm}$ and $290 \mathrm{~nm}$. Both of them show a substantial blue shift with respect to the respective bulk materials (512 $\mathrm{nm}$ for $\mathrm{CdS}, 335 \mathrm{~nm}$ for $\mathrm{ZnS}$ ). The calculations of nanoparticles' radius with Efros model yield the same value of about 1.8-1.9 $\mathrm{nm}$ for both $\mathrm{CdS}$ and $\mathrm{ZnS}$.

The DC I-V characteristics of sandwich structures of $\mathrm{Hg} /$ polyelectrolyte/ITO show the decrease of the conductivity value as the result of $\mathrm{CdS}$ and $\mathrm{ZnS}$ nanoparticles presence in the films, which is believed to be caused by the increase in the film thickness due to the aggregation of nanoparticles and intercalation with polyelectrolytes. C-V measurements for both $\mathrm{CdS}$ and $\mathrm{ZnS}$ show very low capacitances which give the value of dielectric constant of $\epsilon<1$. This indicates that $\mathrm{CdS}$ and $\mathrm{ZnS}$ nanoparticles are conductive which is also supported by G-V measurements. The measurement of capacitance as a function of frequency of both $\mathrm{CdS}$ and $\mathrm{ZnS}$ films show that the capacitance is practically independent of frequency over the range of $10^{2}-10^{6} \mathrm{~Hz}$ which could be another proof of the tunnelling behaviour.

The electroluminescence (EL) from the sandwich structure of $\left(\mathrm{PAH} / \mathrm{CdS} / \mathrm{PAH}_{N}\right.$ was detected using photon counter detector. The luminescence was found to decay rapidly and needs about $10 \mathrm{~s}$ before the sample could be subjected to the next measurement. The study shows that the electroluminescence was started at the input voltage of $1.4 \mathrm{~V}$ and the intensity was increased by increasing the applied voltage.
[1] 1. Wilson M., et al., Nanotechnology : basic science and emerging technologies ( Sydney: Chapman \& Hall/CRC, 2002).

[2] Alivisatos A. P., Journal of Physical Chemistry 100, 1322613239 (1996).

[3] Yoffe A. D., Advances in Physics 51, 799-890(2002).

[4] Murray C. B., Norris D. J., and Bawendi M. G., Journal of the American Chemical Society $115,8706-8715$ (1993).

[5] Kickelbick G., Progress in Polymer Science 28, 83-114 (2003).

[6] Kern W., Schuegraf, Klaus K. 15 August 2007. ihttp://www.williamandrew.com/pdf/1442-chapter.pdf . $_{\text {. }}$

[7 ] Dona J. M., and Herrero J., Thin Solid Films 268, 5-12 (1995).

[8 ] Ramaiah Subba K., Pilkington R. D., Hill A. E., Tomlinson R. D., and Bhatnagar A. K. , Materials Chemistry and Physics 68, 22-30 (2001).

[9 ] Erokhin V., Facci P., Gobbi L., Dante S., Rustichelli F., and Nicolini C., Thin Solid Films 327-329, 503-505 (1998).

[10 ] Erokhina S., Erokhin V., and Nicolini C., Colloids and Surfaces A: Physicochemical and Engineering Aspects 198-200, 645-650.
[11 ] Nabok A. V., Richardson T., Davis F., and Stirling C. J. M., Langmuir 13, 3198-3201 (1997).

[12 ] Nabok A. V., Richardson T., McCartney C., Cowlam N., Davis F., Stirling C. J. M., Ray A. K., Gacem V., and Gibaud A., Thin Solid Films 327-329, 510-514 (1998).

[13 ] Nabok A. V., Iwantono B., Hassan A. K., Ray A. K., and Wilkop T., Materials Science and Engineering C 22, 355-358 (2002).

[14 ] Huang H., Dorn A., Bulovic V., and Bawendi M. G., Applied Physics Letters 90 (2007).

[15 ] Winter J. O., Gomez N., Gatzert S., Schmidt C. E., and Korgel B. A., Colloids and Surfaces A: Physicochemical and Engineering Aspects 254, 147-157 (2005).

[16 ] Hirai T., Sato H., and Komasawa I., Industrial \& Engineering Chemistry Research 33, 3262-3266 (1994).

[17 ] Zhang J., Sun L., Liao C., and Yan C., Solid State Communications 124, 45-48 (2002).

[18 ] Kaltenpoth G., Himmelhaus M., Slansky L., Caruso F., and 
Grunze M., Advanced Materials 15, 1113-1118 (2003).

[19 ] Liang Z., Susha A., and Caruso F., Chemistry of Materials 15, 3176-3183 (2003).

[20 ] Shih-Yuan Lu, Mei-Ling Wu, and Hsin-Lung Chen., Journal of Applied Physics 93, 5789-5793 (2003).

[21 ] Lvov Y., Decher G., and Mohwald H., Langmuir 9, 481-486 (1993).

[22 ] Lvov Y., Haas H., Decher G., Mhwald H., and Kalacbev A., J.Phys.Chem. 97, 12835-12841 (1993).

[23 ] Lvov Y., Essler F., and Decher G., Journal of Physical Chemistry 97, 13773-13777 (1993).

[24 ] Lvov Y. M. and Decher G., Crystallography Reports 39, 628 (1994).

[25 ] Decher G., Lvov Y., and Schmitt J., Thin solid films 244, 772777 (1994).

[26 ] Mao G., Tsao Y., Tirrell M., Davis H., Hessel V., and Ringsdorf H., Langmuir 9,3461-1470 (1993).

[27 ] Tronin A., Lvov Y., and Nicolini C. , Colloid and Polymer Science 272, 1317-1321 (1994).

[28 ] Hong J. D., Lowack K., Schmitt J., and Decher G., Progress in Colloid \& Polymer Science 93, 98-102 (1993).

[29 ] Schmitt J., Grunewald T., Decher G., Pershan P. S., Kjaer K., and Losche M., Macromolecules 26, 7058-7063(1993).

[30 ] Sano M., Lvov Y., and Kunitake T., Ann. Rev. Material Science 26,153-187 (1996).

[31 ] Hammond P. and Whitesides G., Macromolecules 28, 7569$757(1995) 1$.

[32] Yoo D., Shiratori S., and Rubner M., Macromolecules 31, 4309-4318 (1998)

[33 ] Hoogeveen N., Stuart M. C., and Fleer G. , Langmuir 12, 36753681 (1996).

[34 ] Sukhorukov G. B., Mhwald H., Decher G., and Lvov Y. M., Thin Solid Films 284, 220-223 (1996).

[35 ] Decher G. and Schmitt J., Progr. Colloid Polym. Sci. 89, 160 164 (1992).

[36 ] Serizawa T., Hashiguchi S., and Akashi M., Langmuir 15, 5363-5368 (1999).

[37 ] Lvov Y., Ariga K., Onda M., Ichinose I., and Kunitake T., Colloids and Surfaces A: Physicochemical and Engineering Aspects 146, 337-346 (1999).

[38 ] Elbert D. L., Herbert C. B., and Hubbell J. A., Langmuir 15, 5355-5362 (1999)

[39 ] Lowack K. and Helm C. A. , Macromolecules 31, 823-833 (1998).

[40 ] Cooper T. M., Campbell A. L., and Crane R. L., Langmuir 11 , 2713-2718 (1995).

[41 ] Ariga K., Lvov Y., and Kunitake T., Journal of the American Chemical Society 119, 2224-2231 (1997).

[42 ] Lvov Y., Yamada S., and Kunitake T., Thin Solid Films 300, 107-112 (1997).

[43 ] Kotov N. A., De?ka?ny I., and Fendler J. H., Journal of Physical Chemistry 99, 13065-13069 (1995).

[44 ] Schmitt J. and Decher G., Journal of Science, 257-508(1992).

[45 ] Schmitt J., Machtle P., Eck D., Mhwald H., and Helm C. A. , Langmuir 15, 3256- 3266 (1999).

[46 ] Lvov Y., Ariga K., Onda M., Ichinose I., and Kunitake T., Langmuir 13,, 6195-6202 (1997).

[47 ] Liu Y., Wang A., and Claus R. O., Applied Physics Letters 71, 2265 (1997).
[48 ] Caruso F., Lichtenfeld H., Giersig M., and Mohwald H., Journal of the American Chemical Society 120, 8523-8524 (1998).

[49 ] Lvov Y., Ariga K., and Kunitake T., Langmuir 12, 3038-3044 (1996).

[ 50] Ichinose I., Tagawa H., Lvov Y., and Kunitake T., Langmuir 14 , 187-192(1998).

[51 ] Cassagneau T., Fendler J. H., and Mallouk T. E., Langmuir 16, 241-246 (2000).

[52 ] Correa-Duarte M., Giersig M., Kotov N., and Liz-Marzan L., Langmuir 14, 6430- 6435(1998).

[53 ] Chang-Yen D. A., Lvov Y., McShane M. J., and Gale B. K., Sensors and Actuators, B: Chemical 87,336-345 (2002).

[54 ] Fendler J. H., Croatica Chemica Acta 71, 1127-1137 (1998).

[55 ] Ariga K., Lvov Y., Ichinose I., and Kunitake T. , Applied Clay Science 15, 137-152 (1999).

[56 ] Cassier T., Lowack K., and Decher G. , Supramolecular Science 5 , 309-315(1998).

[57 ] Decher G., Lehr B., Lowack K., Lvov Y., and Schmitt J.,Biosensors and Bioelectronics 9, 677-684(1994).

[58 ] Lvov Y., Decher G., and Sukhorukov G. , Macromolecules 26, 5396-5399 (1993).

[59 ] Tsukruk V., Rinderspacher F., and Bliznyuk V., Langmuir 13, 2171-2176 (1997)

[60 ] Caruso F., Niikura K., Furlong N., and Okahata Y., Langmuir 13, 3427-3433 (1997)

[61 ] Caruso F., Furlong D. N., Ariga K., Ichinose I., and Kunitake T., Langmuir 14, 4559-4565 (1998)

[62 ] Ladam G., Schaaf P., Cuisinier F. J. G., Decher G., and Voegel J. C., Langmuir 17,878-882 (2001)

[63 ] Lvov Y., Haas H., Decher G., Mohwald H., and Kalachev A., Langmuir 10,4232-4236 (1994).

[64 ] Lvov Y., Ariga K., Ichinose I., and Kunitake T., Journal of the American Chemical Society 117, 6117-6123(1995).

[65 ] Lvov Y., Ariga K., Ichinose I., and Kunitake T., Thin Solid Films 284, 797-801 (1996).

[66 ] Mitchell K.W., Fahrenbruch A. L., and Bube R. H. , Journal of Applied Physics 48, 4365 (1977)

[67 ] Das S. K. and Morris G. C., Solar energy materials and solar cells 28,305-316 (1993).

[68 ] Britt J. and Ferekides C., Applied Physics Letters 62,2851 (1993).

[69 ] Tang W. and Cameron D. C. , Thin Solid Films 280, 221-226 (1996).

[70] Bol A. A., Ferwerda J., Bergwerff J. A., and Meijerink A. , Journal of Luminescence 99,325-334 (2002).

[71 ] Nanda K. K., Sarangi S. N., and Sahu S.N., Journal of Physics D: Applied Physics 32 , 2306-2310(1999).

[72 ] Lakowicz J. R., Gryczynski I., Gryczynski Z., and Murphy C. J., J. Phys. Chem. B 103, 7613-7620(1999).

[73 ] Nabok A. V. and Hassan A. K., Ray A. K., and Toldi G. N., Materials Science and Engineering C 22, 387-391(2002).

[74 ] Nabok A. V., Massey J., Buttle S., and Ray A. K., IEE Proceedings: Circuits, Devices and Systems 151, 461-46 (2004)5.

[75 ] Suryajaya, A.V. Nabok, A. Tsargorodskaya, A.K. Hassan and F. Davis, Thin Solid Films, 516, pp. 8917-8925 (2008).

[76 ] Suryajaya, A. Nabok, F. Davis, A. Hassan, S.P.J. Higson and J. Evans-Freeman, Applied Surface Science, 254, issue 5, pp. 4891-4898(2008) 